\title{
The impact of acetylsalicylic acid dosed at bedtime on circadian rhythms of blood pressure in the high-risk group of cardiovascular patients-a randomized, controlled trial
}

\author{
Beata Krasińska ${ }^{1}$ (D) Lech Paluszkiewicz ${ }^{2}$ Ewa Miciak-tawicka ${ }^{1}$ Maciej Krasinski ${ }^{3} \cdot$ Piotr Rzymski $^{4,5}$. \\ Andrzej Tykarski ${ }^{1} \cdot$ Zbigniew Krasiński $^{6}$
}

Received: 20 September 2019 / Accepted: 11 September 2020 / Published online: 21 September 2020

(C) The Author(s) 2020

\begin{abstract}
Purpose Time of drug administration may significantly influence its effect. The aim of the present study was to investigate the effect of ASA (administrated in the morning or in the evening) on the anti-hypertensive effect and diurnal blood pressure profile in the high-risk group of cardiovascular patients.

Methods All patients $(n=114)$ had been diagnosed with coronary heart disease and arterial hypertension prior to the enrolment and had been treated with $75 \mathrm{mg}$ per day of ASA in the morning. The patients were randomly assigned to one of the two study groups receiving $75 \mathrm{mg}$ of ASA per day in a single antiplatelet therapy for $3 \mathrm{months}$ in the morning $(n=58)$ or in the evening $(n=56)$. The control group $(n=61)$ consisted of patients with arterial hypertension but without coronary heart disease, not receiving ASA. In all the patients, during each visit, clinical blood pressure (BP) and ambulatory blood pressure measurements (ABPM) were performed.

Results There was a significant reduction in 24-h BP and blood pressure at night in the ASA group evening group compared with the ASA morning group and the control group.

Conclusions The present study demonstrated that compared with the use of ASA in the morning, its administration in the evening may lead to favourable drop in the ABPM and an improvement of the diurnal profile in the high-risk group of cardiovascular patients who are not naïve to ASA.
\end{abstract}

Keywords Acetylsalicylic acid · Anti-hypertensive effect · Bedtime administration · Chronotherapy · Circadian rhythm · Randomized controlled trial

Electronic supplementary material The online version of this article (https://doi.org/10.1007/s00228-020-02997-8) contains supplementary material, which is available to authorized users.

Beata Krasińska

beata.bkrasinska@gmail.com

1 Department of Hypertension, Angiology and Internal Diseases, Poznan University of Medical Sciences, Długa 1/2, 61-848 Poznań, Poland

2 Department of Thoracic And Cardiovascular Surgery/Perioperative diagnostics Bad Oeynhausen, Heart and Diabetes Center NRW, Ruhr-University of Bochum, Bochum, Germany
Imperial College London School of Medicine, London, UK

4 Department of Environmental Medicine, Poznan University of Medical Sciences, Poznan, Poland

5 Integrated Science Association (ISA), Universal Scientific Education and Research Network (USERN), Poznan, Poland

6 Department of General and Vascular Surgery, Poznan University of Medical Sciences, Poznan, Poland 


\section{Introduction}

Acetylsalicylic acid (ASA) is one of the most commonly used drugs in the secondary prevention of coronary arterial disease [1-3]. Nowadays a lot of attention is drawn to the its effect on vascular endothelium in which it inhibits the expression of pro-inflammatory cytokines and leukocyte adhesives, increases the production of nitric oxide, and consequently leads to vasodilatation [4-6]. This effect is further increased by the reduction of production of vasoconstrictive compounds, such as endothelin, thromboxane A2, and prostaglandin. Both of the above-described mechanisms may have an effect on lowering blood pressure, which suggests a pleiotropic mechanism of action of ASA independent of the effect on cyclooxygenase type 1 [4-6]. Patients showing a proper blood pressure drop at night (by 10-20\%) are referred to as dippers [7-10]. A small blood pressure drop characterizes the non-dippers profile at night $(<10 \%)$. This group of patients has an increased incidence of organ damage and an increased risk of cardiovascular complications of arterial hypertension, such as left ventricular hypertrophy and ventricular arrhythmias [11, 12]. Increased systemic pressure at night causes carotid remodelling and glomerular damage, which result in albuminuria and the development of renal failure [13-16]. However low-dose, ASA administration has been documented to exert preventive effects on major cardiovascular events in hypertensive subjects, some studies found no effect on blood pressure profile [17, 18]. One should note that in most cases, ASA was administrated as a single dose in the morning hours or time of its use was not reported $[4,18-20]$. It is now well established that time of drug administration may profoundly influence the effects it is aimed to exert, and this phenomenon also includes anti-hypertensive drugs [7,21,22]. This is due to circadian rhythms, which are governed by a network of hierarchical master clocks present at various locations in the brain and peripheral tissues [23]. Such circadian variation has been also demonstrated for factors such as serum nitric oxide, prostaglandin, plasma renin activity, angiotensin II, and angiotensinconverting enzyme [24-26]. Taking this into consideration it could be hypothesised whether administration of ASA in the morning or evening may differentially affect the change in the diurnal blood pressure profile. To date, only a few studies have addressed the relationship between the time of taking ASA and blood pressure. It was however demonstrated that anti-platelet effect of ASA is more significant after administration in the evening. Moreover, a recent large, multicentre, controlled, prospective endpoint trial has clearly showed that a routine administration of hypotensive medications at bedtime, as opposed to upon waking, results in improved control of blood pressure in hypertensive patients [27]. Nevertheless, in most cases, ASA is taken in one daily dose in the morning hours $[28,29]$.
Therefore, the aim of the present study was to investigate the effect of ASA (administrated in the morning or in the evening) on the anti-hypertensive effect and diurnal blood pressure profile in the high-risk group of cardiovascular patients with coronary heart disease and arterial hypertension.

\section{Material and methods}

The study included 175 patients (59 women and 116 men), aged 59.8 years who were admitted to the Department of Hypertension. The recruitment period was 21 months (from May 2015 to January 2017). From the recruited group, 114 patients had been diagnosed with coronary heart disease (confirmed by angiographic examination) and arterial hypertension prior to the enrolment and had been treated with $75 \mathrm{mg}$ per day of enteric-coated ASA (Acard, Polfa, Poland) in the morning. These patients $(n=114)$ were randomly assigned, in a blinded fashion (a sealed opaque envelope principle), to one of the two study groups receiving $75 \mathrm{mg}$ of ASA per day in a single antiplatelet therapy in the morning $(n=58)$ or in the evening $(n=56)$. To ensure compliance with taking ASA at the specific time, the patients were instructed by the researchers and each patient received a written schedule of drug administration. The control group included 61 patients with arterial hypertension, without coronary heart disease, and not receiving any antiplatelet drugs (Table 1). The study was approved by the Bioethics Committee of Poznan University of Medical Sciences (Approval No. 373/15). Each participant signed informed consent to participate in the study. Exclusion criteria for the study were as follows: secondary hypertension, myocardial infarction and stroke within 6 months prior to the study, chronic heart failure NYHA III and IV, chronic kidney disease (glomerular filtration rate $<$ $60 \mathrm{~mL} / \mathrm{min}$ ), addiction to alcohol and psychotropic substances, active cancer. Additional exclusion criteria for the study group were: confirmed hypersensitivity to ASA, history of bleeding due to ASA, taking clopidogrel or other antiplatelet agents, haemorrhagic diathesis, active gastric and/or duodenal ulcer disease, hypersensitivity to the active substance: ASA, other salicylates, or any component of the drug, using non-steroidal anti-inflammatory drugs. The exclusion criterion for the control group was the use of ASA preparations in the last 30 days. There were no changes in the concomitant treatment (lipid lowering, anti-hypertensive, and antidiabetic), and no non-steroidal anti-inflammatory drugs were taken during the study.

\section{Scheme of the study}

Patients enrolled in the study had two visits in accordance with the prescribed treatment schedule (Fig. 1). On the 1 qualifying visit, the patients had been admitted to the ward where the 
Table 1 Demographic characteristics of the patients. Different superscript letter $(\mathrm{a}, \mathrm{b})$ denote significant differences between groups in each row $(p<0.05$ in multiple comparison post-hoc Dunn test following
Kruskal-Wallis ANOVA). Superscript $\uparrow$ denotes statistically significant difference $(p=0.0000002)$ in Aspirin Reaction Units between Visit 1 and Visit for ASA evening group

\begin{tabular}{|c|c|c|c|c|c|}
\hline & $\begin{array}{l}\text { ASA morning } \\
(n=58)\end{array}$ & $\begin{array}{l}\text { ASA evening } \\
(n=56)\end{array}$ & $\begin{array}{l}\text { Control group } \\
(n=61)\end{array}$ & $p$ value & Statistics \\
\hline Female/male $(n)$ & $19 / 39$ & $19 / 37$ & $21 / 40$ & $>0.05$ & Chi-square \\
\hline Smokers/non-smokers $(n)$ & $14 / 44$ & $17 / 39$ & $17 / 44$ & $>0.05$ & \\
\hline $\begin{array}{l}\text { Age (years) } \\
(\text { mean } \pm \mathrm{SD})\end{array}$ & $59.8 \pm 7.6$ & $60.3 \pm 7.1$ & $59.9 \pm 7.1$ & $>0.05$ & Kruskal-Wallis ANOVA \\
\hline Weight $(\mathrm{kg})($ mean $\pm \mathrm{SD})$ & $84.4 \pm 9.7$ & $84.9 \pm 12.9$ & $84.1 \pm 10.1$ & $>0.05$ & \\
\hline Height $(\mathrm{m})($ mean $\pm \mathrm{SD})$ & $1.69 \pm 0.1$ & $1.69 \pm 0.1$ & $1.69 \pm 0.1$ & $>0.05$ & \\
\hline Body mass index $(\mathrm{kg} / \mathrm{m} 2)($ mean $\pm \mathrm{SD})$ & $29.52 \pm 3.95$ & $29.50 \pm 4.4$ & $29.52 \pm 4.1$ & $>0.05$ & \\
\hline Waist $(\mathrm{cm})($ mean $\pm \mathrm{SD})$ & $93.1 \pm 11.1$ & $92.5 \pm 11.4$ & $93.7 \pm 11.6$ & $>0.05$ & \\
\hline Hip $(\mathrm{cm})($ mean \pm SD) & $105.2 \pm 10.2$ & $105.3 \pm 12.3$ & $105.2 \pm 10.6$ & $>0.05$ & \\
\hline Waist-to-hip ratio (mean $\pm \mathrm{SD}$ ) & $0.88 \pm 0.05$ & $0.87 \pm 0.06$ & $0.89 \pm 0.08$ & $>0.05$ & \\
\hline $\begin{array}{l}\text { Aspirin reaction units visit } 1 \\
(\text { mean } \pm \mathrm{SD})\end{array}$ & $489.0 \pm 73.0^{\mathrm{a}}$ & $488.2 \pm 83.0^{\mathrm{a}}$ & $638.3 \pm 15.9^{\mathrm{b}}$ & $=0.001$ & \\
\hline $\begin{array}{l}\text { Aspirin reaction units visit } 2 \\
(\text { mean } \pm \mathrm{SD})\end{array}$ & $487.62 \pm 77.4^{\mathrm{a}}$ & $460.10 \pm 82.3^{\mathrm{a}} \dagger$ & $639.2 \pm 16.3^{\mathrm{b}}$ & $=0.001$ & \\
\hline
\end{tabular}

laboratory tests, clinical blood pressure and ambulatory blood pressure measurements, imaging examinations and assessment of platelet aggregation using the VerifyNow Aspirin test took place. The randomisation regarding the inclusion of ASA morning or evening was carried out. After 3 months of ASA therapy, Visit 2 was held, during which the examinations from the initial visit were repeated.

\section{Blood pressure measurements}

In all the patients, during each visit, clinical blood pressure measurements were performed three times at rest, in a supine position, in standard conditions, using an upper-arm blood pressure monitor (Omron 705IT). Ambulatory blood pressure measurements were carried out using an A\&D 24-h ambulatory peripheral blood pressure monitor. The frequency of measurements was every 15 min between 7:00 and 22:00, and every $30 \mathrm{~min}$ between 22:00 and 7:00. Subsequently, mean arterial pressure (MAP) was calculated from the formula $\mathrm{MAP}=\mathrm{DBP}+1 / 3(\mathrm{SBP}-\mathrm{DBP})[\mathrm{mm} \mathrm{Hg}]$.

Mean diurnal and nocturnal values of SBP and DBP were analysed. The percentage drop in blood pressure was calculated using the following equations:

$\%$ drop in SBP $=[($ SBP day-SBP night $) / \mathrm{SBP}$ day $] \times 100 \%$ $\%$ drop in $\mathrm{DBP}=[(\mathrm{DBP}$ day-DBP night $) / \mathrm{DPB}$ day $] \times 100 \%$

The night blood pressure fall was calculated as follows:

$\mathrm{NBPF}=[($ MAP day-MAP night $) /$ MAP day $)] \times 100 \%$

Patients with normal NBPF (10-20\%) were referred to as “dippers." Patients with NBPF $<10 \%$ were classified as "non-
Fig. 1 Scheme of the study. Following measurements were performed in each group: laboratory tests, abdominal ultrasound examination, abdominal CT scan, Doppler ultrasound of renal arteries, clinical BP (3x/24 h), ABPM, ECG, echocardiography, weight, and body mass index assessment

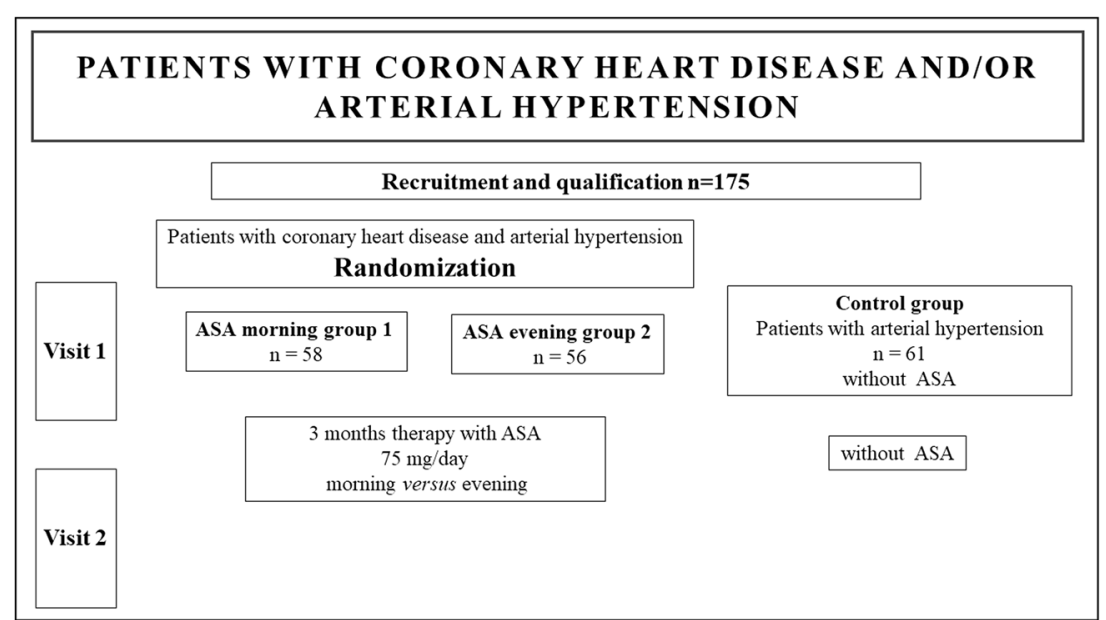


dippers," and patients with NBPF exceeding 20\% were classified as "extreme dippers" [30, 31].

\section{Verify Now Aspirin test}

The Verify Now Aspirin Test method was described in our previous manuscript published in the Cardiology Journal [32].

\section{Statistical analysis}

Statistical analyses were performed with Statistica, version 13.0. (StatSoft, USA). Since the tested data had not met the assumption of Gaussian distribution (evaluated with ShapiroWilk method), non-parametric methods were applied. The Kruskal-Wallis ANOVA test was used for evaluation of the differences in parameters between the three groups. The multiple comparison post-hoc Dunn's test was performed in case $p$ value for Kruskal-Wallis ANOVA was below 0.05 - in such a case a use of different superscripts in tables was applied to denote statistically significant differences between compared groups. Changes in parameters in the individual groups during the first and second visit were analysed using the Wilcoxon signed-rank test - the parametric equivalent of the $t$ test for related variables. Differences between two independent groups were tested with Mann-Whitney U test. Frequencies, expressed on a nominal scale, were analysed based on the Pearson chi-squared test. To evaluate differences in number of dippers, extreme dippers and non-dippers in each group at Visit 1 and Visit, the Fisher's exact test was performed. A $p$ value $<0.05$ was considered significant.

\section{Results}

The basic demographical and clinical characteristics of studied groups of patients are summarized in Table 1 and Table 2. Selected parameters such as body mass index (BMI), weight, waist, and hips did not differ significantly between the studied groups and did not change considerably between Visits 1 and 2 ( $p>0.05$, the Wilcoxon signed-rank test). More importantly, the studied groups did not differ significantly in the amount of administered drugs $(p>0.05$, the Pearson chi-squared test), and there was no change of medications during the study. The results of daytime, night time, and average 24-h BP parameters in the ABPM at the first and second visits are presented in Table 3 . As shown, only a group receiving ASA in the evening for 3 months
Table 2 Comorbidities and pharmaceuticals used in the studied group

\begin{tabular}{|c|c|c|c|}
\hline & ASA morning & ASA evening & Control group \\
\hline \multicolumn{4}{|l|}{ Comorbidity $(n)$} \\
\hline Coronary heart disease & 58 & 56 & 0 \\
\hline Arterial hypertension & 58 & 56 & 61 \\
\hline Diabetes mellitus & 15 & 17 & 14 \\
\hline Metabolic syndrome & 21 & 20 & 22 \\
\hline History of myocardial infarction & 12 & 13 & 0 \\
\hline Previous ischaemic stroke or transient cerebral ischaemia & 5 & 6 & 0 \\
\hline History of coronary artery bypass surgery & 8 & 9 & 0 \\
\hline History of coronary angioplasty & 38 & 37 & 0 \\
\hline Hyperlipidaemia & 58 & 56 & 61 \\
\hline Atherosclerosis of the lower limbs & 7 & 6 & 5 \\
\hline Chronic obstructive pulmonary disease & 6 & 7 & 5 \\
\hline Thyroid disease & 4 & 5 & 5 \\
\hline \multicolumn{4}{|l|}{ Drugs $(n)$} \\
\hline Acetylsalicylic acid & 58 & 56 & 0 \\
\hline Anti-hypertensive drugs & 58 & 56 & 57 \\
\hline$\beta$-blockers & 58 & 56 & 53 \\
\hline Angiotensin-converting enzyme inhibitors & 40 & 34 & 40 \\
\hline Angiotensin II receptor antagonists & 18 & 22 & 21 \\
\hline Calcium antagonists & 22 & 25 & 25 \\
\hline Diuretics/aldosterone antagonists & 13 & 12 & 16 \\
\hline Concomitant lipid-lowering therapy & 58 & 56 & 58 \\
\hline Concomitant antidiabetic therapy (metformin) & 15 & 17 & 14 \\
\hline Proton pump inhibitors & 47 & 45 & 42 \\
\hline
\end{tabular}


Table 3 The results of office blood pressure measurements and parameters of 24-h monitoring (mean $\pm \mathrm{SD}$ ) in the studied groups at Visits 1 and Visit 2. Different superscript letters $(a, b)$ denote significant differences between groups in each row $(p<0.05$ in multiple comparison post-hoc Dunn test following Kruskal-Wallis ANOVA)

\begin{tabular}{|c|c|c|c|c|c|}
\hline & & Kruskal Wallis ANOVA & ASA morning & ASA evening & Control group \\
\hline \multirow[t]{3}{*}{ SBP d [mm Hg] } & Visit 1 & $>0.05$ & $139.1 \pm 6.5$ & $139.4 \pm 7.2$ & $139.2 \pm 6.1$ \\
\hline & Visit 2 & $>0.05$ & $137.9 \pm 5.5$ & $136.5 \pm 6.7$ & $137.8 \pm 5.2$ \\
\hline & p (Wilcoxon) & & $p=0.0014$ & $p=0.0001$ & $p=0.0001$ \\
\hline \multirow[t]{3}{*}{ DBP d [mm Hg] } & Visit 1 & $>0.05$ & $86.5 \pm 5.2$ & $86.4 \pm 5.4$ & $86.8 \pm 5.1$ \\
\hline & Visit 2 & $>0.05$ & $84.9 \pm 5.2$ & $84.3 \pm 6.2$ & $85.7 \pm 5.5$ \\
\hline & p (Wilcoxon) & & $p=0.0048$ & $p=0.0001$ & $p<0.0001$ \\
\hline \multirow[t]{3}{*}{ MAP d [mm Hg] } & Visit 1 & $>0.05$ & $104.1 \pm 4.5$ & $104.1 \pm 4.9$ & $104.3 \pm 4.2$ \\
\hline & Visit 2 & $>0.05$ & $102.6 \pm 4.0$ & $101.7 \pm 5.2$ & $102.4 \pm 4.5$ \\
\hline & p (Wilcoxon) & & $p=0.0001$ & $p=0.0001$ & $p=0.0001$ \\
\hline \multirow[t]{3}{*}{ SBPn $[\mathrm{mm} \mathrm{Hg}]$} & Visit 1 & $>0.05$ & $125.7 \pm 7.3$ & $125.6 \pm 7.0$ & $125.2 \pm 6.8$ \\
\hline & Visit 2 & $<0.05$ & $125.2 \pm 7.0^{\mathrm{a}}$ & $120.1 \pm 6.9^{b}$ & $125.7 \pm 6.6^{\mathrm{a}}$ \\
\hline & p (Wilcoxon) & & $p>0.05$ & $p=0.0001$ & $p<0.05$ \\
\hline \multirow{3}{*}{$\begin{array}{l}\mathrm{DBPn} \\
{[\mathrm{mm} \mathrm{Hg}]}\end{array}$} & Visit 1 & $>0.05$ & $79.5 \pm 5.3$ & $79.1 \pm 4.7$ & $79.1 \pm 4.9$ \\
\hline & Visit 2 & $<0.05$ & $78.4 \pm 4.6^{\mathrm{a}}$ & $74.5 \pm 5.3^{b}$ & $78.4 \pm 5.2^{\mathrm{a}}$ \\
\hline & $\mathrm{p}$ (Wilcoxon) & & $p>0.05$ & $p=0.0001$ & $p>0.05$ \\
\hline \multirow[t]{3}{*}{ MAPn $[\mathrm{mm} \mathrm{Hg}]$} & Visit 1 & $>0.05$ & $94.6 \pm 4.2$ & $94.6 \pm 4.0$ & $94.5 \pm 4.1$ \\
\hline & Visit 2 & $<0.05$ & $94.0 \pm 3.8^{\mathrm{a}}$ & $89.7 \pm 4.6^{b}$ & $94.2 \pm 4.0^{\mathrm{a}}$ \\
\hline & p (Wilcoxon) & & $p>0.05$ & $p=0.0001$ & $p>0.05$ \\
\hline \multirow[t]{3}{*}{ SBP 24 [mm Hg] } & Visit 1 & $>0.05$ & $134.6 \pm 6.2$ & $134.4 \pm 6.8$ & $134.6 \pm 6.3$ \\
\hline & Visit 2 & $<0.05$ & $132.8 \pm 5.7^{\mathrm{a}}$ & $128.9 \pm 5.8^{b}$ & $134.2 \pm 4.9^{\mathrm{a}}$ \\
\hline & p (Wilcoxon) & & $p>0.05$ & $p=0.0001$ & $p>0.05$ \\
\hline \multirow[t]{3}{*}{ DBP $24[\mathrm{~mm} \mathrm{Hg}]$} & Visit 1 & $>0.05$ & $82.6 \pm 4.4$ & $82.3 \pm 4.8$ & $83.2 \pm 5.1$ \\
\hline & Visit 2 & $<0.05$ & $82.3 \pm 4.1^{\mathrm{a}}$ & $78.7 \pm 5.9^{b}$ & $83.1 \pm 5.5^{\mathrm{a}}$ \\
\hline & p (Wilcoxon) & & $p>0.05$ & $p=0.0001$ & $p>0.05$ \\
\hline \multirow[t]{3}{*}[\mathrm{mm}\mathrm{Hg}]{} & Visit 1 & $>0.05$ & $100.0 \pm 3.9$ & $99.7 \pm 4.4$ & $100.3 \pm 4.6$ \\
\hline & Visit 2 & $<0.05$ & $99.2 \pm 3.6^{\mathrm{a}}$ & $95.5 \pm 5.1^{\mathrm{b}}$ & $100.2 \pm 4.3^{\mathrm{a}}$ \\
\hline & p (Wilcoxon) & & $p>0.05$ & $p=0.0001$ & $p>0.05$ \\
\hline \multirow[t]{3}{*}{$\mathrm{NBPF}[\%]$} & Visit 1 & $>0.05$ & $9.0 \pm 3.0$ & $9.1 \pm 2.5$ & $9.3 \pm 2.8$ \\
\hline & Visit 2 & $<0.05$ & $8.3 \pm 2.8^{\mathrm{a}}$ & $11.8 \pm 2.7^{\mathrm{b}}$ & $7.9 \pm 3.6^{\mathrm{a}}$ \\
\hline & p (Wilcoxon) & & $p=0.032$ & $p=0.0001$ & $p=0.0002$ \\
\hline \multirow[t]{3}{*}{ Clinic SBP $[\mathrm{mm} \mathrm{Hg}]$} & Visit 1 & $>0.05$ & $145.5 \pm 5.0$ & $145.2 \pm 6.7$ & $145.1 \pm 5.2$ \\
\hline & Visit 2 & $<0.05$ & $143.0 \pm 4.1^{\mathrm{a}}$ & $139.8 \pm 5.6^{\mathrm{b}}$ & $144.2 \pm 4.6^{\mathrm{a}}$ \\
\hline & p (Wilcoxon) & & $p=0.0001$ & $p=0.0001$ & $p>0.05$ \\
\hline \multirow[t]{3}{*}{ Clinic DBP $[\mathrm{mm} \mathrm{Hg}]$} & Visit 1 & $>0.05$ & $88.8 \pm 4.0$ & $88.8 \pm 5.3$ & $89.0 \pm 5.5$ \\
\hline & Visit 2 & $<0.05$ & $87.2 \pm 4.7^{\mathrm{a}}$ & $85.0 \pm 5.7^{\mathrm{b}}$ & $87.9 \pm 3.0^{\mathrm{a}}$ \\
\hline & p (Wilcoxon) & & $p=0.004$ & $p=0.0001$ & $p>0.05$ \\
\hline
\end{tabular}

SBPd, ambulatory daytime systolic blood pressure; DBPd, ambulatory daytime diastolic blood pressure; MAPd, ambulatory daytime mean blood pressure; SBPn, ambulatory nighttime systolic blood pressure; DBPn, ambulatory nighttime diastolic blood pressure; MAPn, ambulatory nighttime mean blood pressure; SBP24, 24-h systolic blood pressure; DBP24, 24-h diastolic blood pressure; MAP24, 24-h ambulatory mean blood pressure; NBPF, night blood pressure fall; clinic SBP, systolic blood pressure; clinic DBP, diastolic blood pressure

revealed a significant decrease in the blood pressure at night (SBPn by $5.5 \mathrm{mmHg}$, DBPn by $4.6 \mathrm{mmHg}$ and MAPn by $4.9 \mathrm{mmHg}$ ) and in the 24-h BP measurements (SBP24 by $5.5 \mathrm{mmHg}$, DBP24 by $3.56 \mathrm{mmHg}$ and MAP2 4 by $4.2 \mathrm{mmHg}$ ). Although the group receiving ASA in the morning revealed a decrease in the clinic BP (by $2.5 / 1.7 \mathrm{mmHg}$ ), the statistically higher drop was displayed by patients using ASA in the evening (by 5.4/3.8 $\mathrm{mmHg}$ ) (Table 3). As shown in Table 3 and Fig. 2, only the group receiving ASA in the evening experienced a significant increase in the NBPF between Visit 1 and Visit 2 (by mean of 3.5\%), while in the control group and the group with morning ASA administration, the opposite trend was 


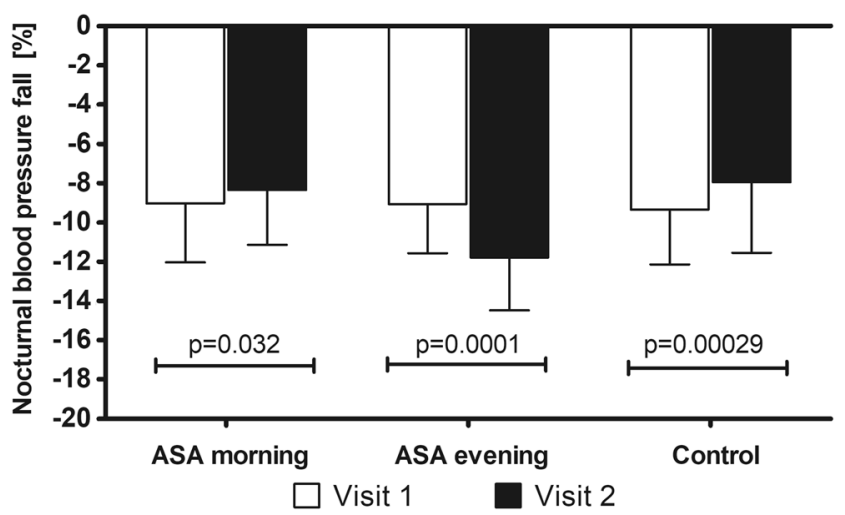

Fig. 2 Changes of nocturnal blood pressure fall between Visit 1 and Visit 2 in the studied groups ( $p$ value refers to Wilxocon-signed rank test)

noted. A mean NBPF at Visit 2 was 8.3 and $7.9 \%$ in the ASA morning and control group, respectively, and $11.8 \%$ in the ASA evening group. A beneficial change observed in the latter group was relevant enough to significantly increase the number of dippers in this group - nearly threefold, from 14 patients at Visit 1 to 39 patients at Visit 2. In the case of the group with morning ASA administration, a decrease in patients identified as dippers was observed-from 22 at Visit 1 to only 16 at Visit 2 (Fig. 3). The statistically significant difference in BMI between non-dippers and dippers was revealed in the ASA evening group with a mean $\pm \mathrm{SD}$ of $31.4 \pm 4.4$ and $28.6 \pm 44.1$ (Mann-Whitney $\mathrm{U}$ test, $p=$ 0.04). The laboratory results for each group at Visit 1 and Visit 2 are presented in Table S1. None of the considered parameters was altered in all groups except uric acid, which concentration at Visit 2 was increased in the group receiving ASA in the evening when compared with that at Visit 1 (Table S1).

\section{Discussion}

The present study demonstrated the clinic blood pressure drop after 3 months of evening ASA administration in patients with arterial hypertension coronary heart disease who were already taking ASA. More importantly, the same has been confirmed in ABPM. There was a significant reduction in the average 24$\mathrm{h}$ BP (SBP24, DBP24 and MAP24) and night blood pressure (SBPn, DBPn, MAPn) in the ASA evening group compared with the ASA morning group and the control group. Interestingly, during the day hours, there was a statistically significant decrease in systolic, diastolic, and average 24-h BP in both groups: ASA morning and ASA evening. This could be due to the antihypertensive drugs used by patients on their own although the nocturnal BP drop found only in the evening group highlights a favourable chronotherapeutic effect of ASA and advocates its use at bedtime in subjects with arterial hypertension and coronary heart disease.

The anti-hypertensive mechanism of ASA is not fully understood. During the night, there is a physiological drop in blood pressure, which causes a decrease in perfusion through the kidneys, and this is a signal for the activation of the reninangiotensin-aldosterone (RAA) system. The beneficial effect of ASA administration in the evening can be explained by the effect of inhibiting the increase of RAA system activity, as well as the beneficial effects on the production of nitric oxide [33]. Snoep et al. have shown that taking ASA at bedtime compared with morning administration reduced the mean plasma renin activity without affecting aldosterone levels. The excretion of cortisol, dopamine, and norepinephrine in diurnal urine collection was lower in the group of patients treated with ASA given in the evening. The activity of RAA system, cortisol levels, and catecholamines follows a circadian rhythm, peaking in the early morning hours. This allows the assumption that the administration of ASA in the morning would be too late. Thus, taking ASA at bedtime can be considered as the right moment to harness the additional antihypertensive effects of this drug [34].

The results published by Hermida et al., which refer to a group of 328 subjects with mild, non-treated hypertension, are
Fig. 3 The number of nondipping, dipping, and extremely dipping patients in the studied groups during the Visit 1 and Visit 2 ( $p$ value refers to Fisher's exact test)

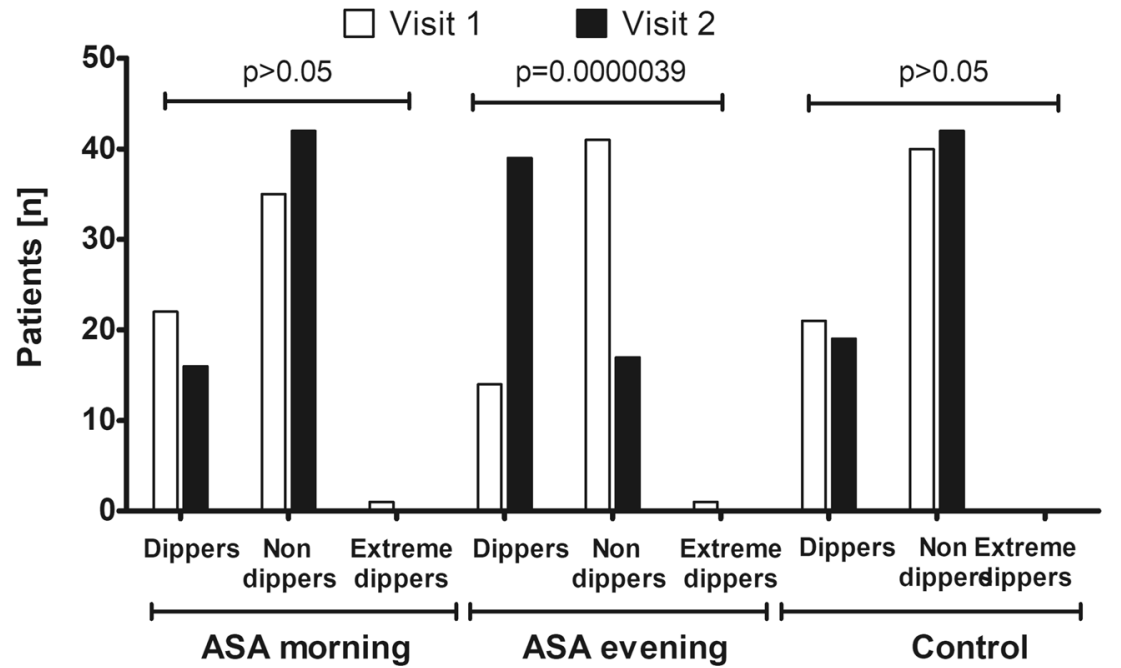


concordant with the results obtained in the present study. In the referenced study, after 3 months of ASA administration in the morning and in the evening, in the ASA evening group a significant drop in blood pressure was obtained in clinical and ABPM measurements. ASA belongs to the group of nonsteroidal anti-inflammatory drugs, which by inhibiting cyclooxygenase type 1 and type 2 causes an increase in blood pressure $[3,18,35]$. Therefore, the results obtained by Hermida et al. were considered surprising and unexpected. However, the same researcher team obtained similar results in three consecutive studies in pregnant women and patients with prehypertension [36-38]. In turn, the present study adds that ASA administration at bedtime, contrary to morning ingestion, results in better effect on blood pressure in patients suffering from arterial hypertension and coronary heart disease, who are not naïve to ASA.

Chronotherapy with ASA is poorly understood and contradictory reports have been published so far. In contrast to the results of the present study, Magen et al. described the antihypertensive effect of ASA after morning drug administration. They have shown that the addition of low-dose ASA to antihypertensive drugs in patients with hypertension and hypercholesterolemia may reduce both SBP and DBP as well as improve endothelial function, measured by the ability of the brachial artery to dilate [39]. The probable mechanism by which ASA lowers BP is its effect on reducing vasoconstriction through inhibition of TXA2 production, as well as increasing production of nitric oxide causing vasodilation. However, in our previous study, we have not found any reduction in blood pressure following a 4-week treatment with ASA compared with standardized tomato extract $(213 \mathrm{mg} /$ day). Both drugs were administered in the morning, and the treatment group included patients of high and very high cardiovascular risk [40]. Similar results were published by Avazini et al. who did not observe a decrease in SBP and DBP in patients treated for hypertension with a low-dose ASA administered in the morning [19]. In a randomized study, a group of 290 patients showed no decrease in blood pressure despite the use of ASA in the evening, while a reduction in platelet reactivity was observed in the Verify Now Aspirin test [41]. The above data suggest that the effect of ASA on blood pressure may be dependent on the time of dosing and independent of antiplatelet activity.

Through the use of ABPM, this study draws attention to the effect of ASA not only on a single blood pressure measurement but also on the diurnal blood pressure profile. Compared with the ASA morning group, in the ASA evening group there was a significant increase in nocturnal blood pressure drop. Paradoxically, in the ASA morning group, there was a slight decrease in the NBPF value, which meant that the patients still had a non-dippers profile. This observation may be of clinical significance because for patients in whom the pressure drop at the night does not exceed 10-20\% (non-dippers); there exists a greater risk of developing subclinical organ damage [14, 42]. The relationship between lack of blood pressure drop at night and risk of cardiovascular events was confirmed in many studies $[12,16,43]$. In their studies, Verdecchia et al. and Syst-Eur showed that non-dippers hypertensive patients experienced more frequent cardiovascular events, compared with the dippers group [44-46]. Hermida et al. showed that patients who received ASA at bedtime demonstrated a more significant BP reduction at night in the non-dippers group. Together with the current results, this can be considered a confirmation of the time-dependent dosage of ASA on blood pressure, mainly in non-dippers [47]. The data obtained in the current study suggest a significant effect and role of bedtime ASA administration in the group of patients with coronary heart disease and arterial hypertension. The demonstrated hypotensive effect of ASA when used in the evening allows ASA to be included in the group of chronotherapeutics, i.e., the drugs with a timedependent effect. Interestingly, in our previous work, we showed a significant reduction in platelet aggregation by 28 ARUs in the ASA evening group, which was determined using the Verify Now analyser. At baseline visit, the results of inhibition of aggregation in ARUs did not differ between the groups. This confirms the effect of a low-dose ASA taken at bedtime on the reduction of COX-1-dependent platelet activity. Since the anti-aggregation and anti-hypertensive effect occurred only in the patients taken ASA at bedtime, this may indicate that the mechanism of BP drop and platelet function is common and probably can be associated with COX-1 inhibition [32]. Interestingly, the non-dipping patients in the group receiving ASA at bedtime displayed significantly higher BMI as compared with the individuals revealing dipping pattern. The present study has employed enteric coated form of ASA (which is the most prevalent form of ASA in Poland) and previous investigations has shown that patients' weight can modify the response to this formparticularly individuals with higher Weight may be less susceptible to its effects [48, 49].

There are number of hypothetical explanations for the observed night drop in BP following the bedtime administration of ASA. Firstly, it may be possible that the activity of COX in endothelium and other tissues is higher during the night, thus explaining the more profound effect of ASA on its inhibition. Secondly, if BP at night is associated with higher platelets activation, the anti-platelet action of ASA may explain the night time reduction in BP. Finally, there may be a difference in ASA metabolism between night and day, with higher ASA inactivation to salicylate during the day. Indeed, studies addressing the circadian rhythms on the kinetics of drugs indicate that their night time metabolism is usually significantly lower [50] Therefore, the night time may represent a window in which ASA effects on COX and platelets may be more profound, eventually inducing a drop in BP. However, all of these hypothesis require further studies to understand the 
exact mechanisms behind the night time effect of ASA on BP. It would be of high interest to conduct a study with and similar model in which clopidogrel is used instead of ASA. Clopidogrel is a more potent irreversible anti-platelet agent which binds to P2Y12 ADP receptor although it does not inhibit COX [51]. This would allow to test to which extent $\mathrm{COX}$ or platelets activity during the night time are involved in changes of BP at night in human. Further valuable information could be derived by including, additionally to platelet aggregometry, an investigation of serum thromboxane B2 levels which can provide a direct measure of the pharmacological effect of ASA and may be even more predictive when performed in tandem with a global measure of platelet function $[49,52]$.

\section{Conclusion}

The present study demonstrated that compared with the use of ASA in the morning, its administration in the evening may lead to favourable drop in the ABPM and an improvement of the diurnal profile in the high-risk group of cardiovascular patients suffering from arterial hypertension and coronary heart disease who are not naïve to ASA.

Author's contribution BK, LP, AT, and ZK contributed to the study design. BK and EML were involved in data collection. BK, LP, MK, and PR contributed to the data interpretation and statistical analysis. All authors edited and approved the final version of the manuscript.

\section{Compliance with ethical standards}

Conflict of interest The authors declare that they have no conflict of interest.

Ethical approval All procedures performed in studies involving human participants were in accordance with the ethical standards of the institutional and/or national research committee (the Bioethics Committee of Poznan University of Medical Sciences (Approval No. 373/15) and with the 1964 Helsinki declaration and its later amendments or comparable ethical standards.

Informed consent Additional informed consent was obtained from all individual participants for whom identifying information is included in this article.

Open Access This article is licensed under a Creative Commons Attribution 4.0 International License, which permits use, sharing, adaptation, distribution and reproduction in any medium or format, as long as you give appropriate credit to the original author(s) and the source, provide a link to the Creative Commons licence, and indicate if changes were made. The images or other third party material in this article are included in the article's Creative Commons licence, unless indicated otherwise in a credit line to the material. If material is not included in the article's Creative Commons licence and your intended use is not permitted by statutory regulation or exceeds the permitted use, you will need to obtain permission directly from the copyright holder. To view a copy of this licence, visit http://creativecommons.org/licenses/by/4.0/.

\section{References}

1. Magagna A, Abdel-Haq B, Favilla S, Taddei S, Salvetti A (1994) Hemodynamic and humoral effects of low-dose aspirin in treated and untreated essential hypertensive patients. Blood Press 3(4): 236-241

2. Wirtwein M, Gruchala M, Sobiczewski W (2017) Diurnal blood pressure profile and coronary atherosclerosis extent are related to cardiovascular complications. Blood Press 26(2):81-86

3. Czyz M, Watala C (2005) Aspirin-the prodigious panacea? Molecular mechanisms of the action of acetylsalicylic acid in the organism. Postepy Hig Med Dosw (Online) 59:105-115

4. Monobe H, Yamanari H, Nakamura K, Ohe T (2001) Effects of low-dose aspirin on endothelial function in hypertensive patients. Clin Cardiol 24(11):705-709

5. Buga GM, Gold ME, Fukuto JM, Ignarro LJ (1991) Shear stressinduced release of nitric oxide from endothelial cells grown on beads. Hypertension 17(2):187-193

6. Madajka M, Korda M, White J, Malinski T (2003) Effect of aspirin on constitutive nitric oxide synthase and the biovailability of NO. Thromb Res 110(5-6):317-321

7. Felip-Benach A, Sobrino-Martinez J (2006) Chronotherapy of arterial hypertension. Med Clin (Barc) 126(10):378-379

8. Verdecchia P, Borgioni C, Ciucci A, Gattobigio R, Schillaci G, Sacchi N, Santucci A, Santucci C, Reboldi G, Porcellati C (1996) Prognostic significance of blood pressure variability in essential hypertension. Blood Press Monit 1(1):3-11

9. White WB (1997) Circadian variation of blood pressure: clinical relevance and implications for cardiovascular chronotherapeutics. Blood Press Monit 2(1):47-51

10. Tykarski A, Narkiewicz K, Gaciong Z et al (2015) Guidelines for the management of hypertension. Recommendations of the polish Society of Hypertension - short version. Kardiol Pol 73(8):676-700

11. Calhoun DA, Zhu S, Wyss JM, Oparil S (1994) Diurnal blood pressure variation and dietary salt in spontaneously hypertensive rats. Hypertension 24(1): 1-7

12. Verdecchia P, Schillaci G, Guerrieri M, Gatteschi C, Benemio G, Boldrini F, Porcellati C (1990) Circadian blood pressure changes and left ventricular hypertrophy in essential hypertension. Circulation 81(2):528-536

13. Timio M, Venanzi S, Lolli S, Lippi G, Verdura C, Monarca C, Guerrini E (1995) "Non-dipper" hypertensive patients and progressive renal insufficiency: a 3-year longitudinal study. Clin Nephrol 43(6):382-387

14. Di Daniele N, Fegatelli DA, Rovella V et al (2017) Circadian blood pressure patterns and blood pressure control in patients with chronic kidney disease. Atherosclerosis 267:139-145

15. Krzych LJ, Bochenek A (2013) Blood pressure variability: epidemiological and clinical issues. Cardiol J 20(2):112-120

16. Mancia G, Parati G (2003) The role of blood pressure variability in end-organ damage. J Hypertens Suppl 21(6):S17-S23

17. Hansson L, Zanchetti A, Carruthers SG et al (1998) Effects of intensive blood-pressure lowering and low-dose aspirin in patients with hypertension: principal results of the hypertension optimal treatment (HOT) randomised trial. HOT Study Group. Lancet 351(9118):1755-1762

18. Zanchetti A, Hansson L, Dahlof B et al (2002) Benefit and harm of low-dose aspirin in well-treated hypertensives at different baseline cardiovascular risk. J Hypertens 20(11):2301-2307

19. Avanzini F, Palumbo G, Alli C, Roncaglioni MC, Ronchi E, Cristofari M, Capra A, Rossi S, Nosotti L, Costantini C, Pietrofeso R, Collaborative Group of the Primary Prevention Project (PPP)-Hypertension study (2000) Effects of low-dose aspirin on clinic and ambulatory blood pressure in treated hypertensive 
patients. Collaborative Group of the Primary Prevention Project (PPP)-hypertension study. Am J Hypertens 13(6 Pt 1):611-616

20. Nawarskas JJ, Townsend RR, Cirigliano MD et al (1999) Effect of aspirin on blood pressure in hypertensive patients taking enalapril or losartan. Am J Hypertens 12(8 Pt 1):784-789

21. Smolensky MH, Portaluppi F (1999) Chronopharmacology and chronotherapy of cardiovascular medications: relevance to prevention and treatment of coronary heart disease. Am Heart J 137(4 Pt 2):S14-S24

22. Bendersky M (2015) Chronotherapy in arterial hypertension. Hipertens Riesgo Vasc 32(3):119-124

23. Kaur G, Phillips CL, Wong K et al (2016) Timing of Administration: For Commonly-Prescribed Medicines in Australia. Pharmaceutics 8(2)

24. Kanabrocki EL, George M, Hermida RC, Messmore HL, Ryan MD, Ayala DE, Hoppensteadt DA, Fareed J, Bremner FW, Third JLHC, Shirazi P, Nemchausky BA (2001) Day-night variations in blood levels of nitric oxide, T-TFPI, and E-selectin. Clin Appl Thromb Hemost 7(4):339-345

25. Angeli A, Gatti G, Sartori ML, Masera RG (1992) Chronobiological aspects of the neuroendocrine-immune network. Regulation of human natural killer (NK) cell activity as a model. Chronobiologia 19(3-4):93-110

26. Cermakian N, Westfall S, Kiessling S (2014) Circadian clocks and inflammation: reciprocal regulation and shared mediators. Arch Immunol Ther Exp 62(4):303-318

27. Hermida RC, Crespo JJ, Domínguez-Sardiña M, Otero A, Moyá A, Ríos MT et al (2019) Bedtime hypertension treatment improves cardiovascular risk reduction: the Hygia Chronotherapy Trial. Eur Heart J:ehz754

28. Wurtz M, Hvas AM, Jensen LO et al (2014) 24-hour antiplatelet effect of aspirin in patients with previous definite stent thrombosis. Int J Cardiol 175(2):274-279

29. Cornelissen G, Halberg F, Prikryl P et al (1991) Prophylactic aspirin treatment: the merits of timing. International Womb-to-Tomb Chronome Study Group. JAMA 266(22):3128-3129

30. Pickering TG (1990) The clinical significance of diurnal blood pressure variations. Dippers and nondippers. Circulation 81(2): 700-702

31. Kario K, Shimada K (2004) Risers and extreme-dippers of nocturnal blood pressure in hypertension: anti-hypertensive strategy for nocturnal blood pressure. Clin Exp Hypertens 26(2):177-189

32. Krasinska B, Paluszkiewicz L, Miciak-Lawicka E et al (2018) The effect of acetylsalicylic acid dosed at bedtime on the antiaggregation effect in patients with coronary heart disease and arterial hypertension: a randomized, controlled trial. Cardiol J

33. Gordon RD, Wolfe LK, Island DP, Liddle GW (1966) A diurnal rhythm in plasma renin activity in man. J Clin Invest 45(10):15871592

34. Snoep JD, Hovens MM, Eikenboom JC, van der Bom J, Huisman MV (2007) Association of laboratory-defined aspirin resistance with a higher risk of recurrent cardiovascular events: a systematic review and meta-analysis. Arch Intern Med 167(15):1593-1599

35. Hermida RC, Ayala DE, Calvo C, López JE (2005) Aspirin administered at bedtime, but not on awakening, has an effect on ambulatory blood pressure in hypertensive patients. J Am Coll Cardiol 46(6):975-983

36. Hermida RC, Ayala DE, Mojon A, Fernandez JR (2009) Ambulatory blood pressure control with bedtime aspirin administration in subjects with prehypertension. Am J Hypertens 22(8): 896-903
37. Hermida RC, Ayala DE, Iglesias M et al (1997) Time-dependent effects of low-dose aspirin administration on blood pressure in pregnant women. Hypertension 30(3 Pt 2):589-595

38. Hermida RC, Ayala DE, Fernandez JR et al (1999) Administration time-dependent effects of aspirin in women at differing risk for preeclampsia. Hypertension 34(4 Pt 2):1016-1023

39. Magen E, Viskoper JR, Mishal J, Priluk R, London D, Yosefy C (2005) Effects of low-dose aspirin on blood pressure and endothelial function of treated hypertensive hypercholesterolaemic subjects. J Hum Hypertens 19(9):667-673

40. Krasinska B, Osinska A, Krasinska A et al (2018) Favourable hypotensive effect after standardised tomato extract treatment in hypertensive subjects at high cardiovascular risk: a randomised controlled trial. Kardiol Pol 76(2):388-395

41. Bonten TN, Snoep JD, Assendelft WJ et al (2015) Time-dependent effects of aspirin on blood pressure and morning platelet reactivity: a randomized cross-over trial. Hypertension 65(4):743-750

42. O'Brien E, European Society M (2003) Of hypertension working group on blood pressure, The Working Group on Blood Pressure Monitoring of the European Society of Hypertension. Blood Press Monit 8(1):17-18

43. Bendzala M, Kruzliak P, Gaspar L, Soucek M, Mrdovic I, Sabaka P, Dukat A, Gasparova I, Malan L, Takazawa K (2015) Prognostic significance of dipping in older hypertensive patients. Blood Press 24(2):103-110

44. Verdecchia P, Garofoli M, Angeli F, Reboldi G (2013) Response to morning surge, dipping, and sleep-time blood pressure as prognostic markers of cardiovascular risk. Hypertension 61(1):e4

45. Staessen JA, Thijs L, Birkenhager WH et al (1999) Update on the systolic hypertension in Europe (Syst-Eur) trial. The Syst-Eur Investigators. Hypertension 33(6):1476-1477

46. Fagard R, Staessen J, Thijs L, Amery A (1991) Prognostic significance of exercise versus resting blood pressure in hypertensive men. Hypertension 17(4):574-578

47. Hermida RC, Ayala DE, Calvo C et al (2005) Differing administration time-dependent effects of aspirin on blood pressure in dipper and non-dipper hypertensives. Hypertension 46(4):1060-1068

48. Peace A, McCall M, Tedesco T et al (2010) The role of weight and enteric coating on aspirin response in cardiovascular patients. $\mathrm{J}$ Thromb Haemost 8(1):2323-2325

49. McCall M, Peace A, Tedesco A et al (2019) Weight as an assayindependent predictor of poor response to enteric aspirin incardiovascular patients. Platelets 31:530-535. https://doi.org/10. 1080/09537104.2019.1667495

50. Baraldo M (2008) The influence of circadian rhythms on the kinetics of drugs in humans. Expert Opin Drug Metab Toxicol 4(2):175192

51. Serebruany VL, Steinhubl SR, Berger PB, Malinin AI, Bhatt DL, Topol EJ (2005) Variability in platelet responsiveness to clopidogrel among 544 individuals. J Am Coll Cardiol 45(2): 246-251

52. Kidson-Gerber G, Weaver J, Gemmell R, Prasan AM, Chong BH (2010) Serum thromboxane B 2 compared to five other platelet function tests for the evaluation of aspirin. Heart Lung Circ 19(4): 234-242

Publisher's note Springer Nature remains neutral with regard to jurisdictional claims in published maps and institutional affiliations. 